\section{FORMAÇÕES DO SUJEITO COLONIAL: SUPLEMENTO, DEPENDÊNCIA, COSMOPOLITISMO ${ }^{1}$}

\author{
FORMATIONS OF THE COLONIAL SUBJECT: \\ SUPPLEMENT, DEPENDENCE, COSMOPOLITISM \\ João Camillo Penna
}

UFRJ

Rio de Janeiro, RJ, Brasil

\title{
Resumo
}

O artigo parte da cena paradigmática da etnologia "brasileira" vista a partir da Europa, que reivindica a sua parte na constituição de um modelo de descentramento no interior da mesma Europa. Essa cena servirá de base para estudar os ensaios matriciais de Silviano Santiago, em que se trata precisamente de estabelecer os fundamentos de uma crítica colonial do sujeito cultural brasileiro.

\section{Résumé}

Larticle prend son point de départ dans une scène paradigmatique de l'ethnologie "brésilienne" telle qu'elle est vue de l'Europe, qui revendique sa partie dans la constitution d'un modèle excentrique à l'intérieur de l'Europe elle-même. Cette scène servira de base pour l'étude de certains essais classiques de Silviano Santiago, où il s'agit précisément d'établir les fondements d'une critique coloniale du sujet culturel brésilien.

\section{Abstract}

The article takes its cue from the paradigmatic scene of the "Brazilian" ethnography, as seen from Europe, which demands its share in the constitution of a model of decentralization within Europe itself. This scene will serve as the basis in order to study seminal essays by Silviano Santiago, where what is at stake is establishing the foundations of a colonial critique of the Brazilian cultural subject.

Eduardo Viveiros de Castro, em artigo em que revê os aportes teóricos da "etnografia brasileira", conta uma cena que nos servirá de entrada ao nosso tema de hoje. Encontrava-se o antropólogo brasileiro em um simpósio de história da cultura em Manchester, Reino Unido, apresentando uma comunicação sobre o perspecti-

\footnotetext{
${ }^{1}$ Uma versão dste artigo foi apresentada sob a forma de comunicação no Seminário "Crítica e valor". Homenagem a Silviano Santiago, organizado por Célia Pedrosa, Tânia Dias e Flora Süssekind, na Fundação Casa de Rui Barbosa, em outubro de 2006.
}

Palavras-chave: Silviano Santiago; desconstrução; sujeito colonial; formação.

Mots-clés: Silviano Santiago; déconstruction; sujet colonial; formation.

Keywords: Silviano Santiago; deconstruction; colonial subject; self-fashioning. 
(CASTRO, Eduardo Viveiros de. "Etnologia brasileira". Em: O que ler na ciência social brasileira (19701995). Antropologia (volume I) Miceli, Sergio (org.). São Paulo: Editora Sumaré: ANPOCS; Brasília, DF: CAPES, 1999: 152.)

vismo ameríndio quando, durante o debate, é interpelado por um dos participantes com a seguinte provocação: "Seu trabalho é muito interessante; mas seus índios parecem ter estudado em Paris".* A resposta de Eduardo Viveiros de Castro, que poderia ter saído do Manifesto antropófago de Oswald de Andrade, e, pour cause, a mais de um título, dá o tom de uma certa estratégia intelectual cosmopolita brasileira. Escreve ele:

Respondi que, na realidade, havia ocorrido exatamente o contrário: que alguns parisienses haviam estudado na Amazônia. Argumentei que minha análise devia tanto ao estruturalismo francês quanto este antes à etnologia brasileira e, dessa forma, aos "meus" índios: não fora o Pará que estivera em Paris, mas sim Paris no Pará.*

A estratégia é conhecida, embora formulada aqui, em local privilegiado: a antropologia, e especificamente a etnologia brasileira, onde a "substituição de importaçôes" - termo da teoria da dependência, citado por Viveiros de Castro no artigo em questão - se completara no Brasil de forma bastante significativa, é, dentro das ciências humanas, talvez a única que fale de igual para igual para com a comunidade científica mundial. Embora o possessivo "meus" ou "seus" indios, referido ironicamente na pergunta e na resposta, não indique acesso privilegiado ao indígena que vive em território brasileiro, e remeta a um tema fundamental da crítica etnológica ao estado-nação, já que os índios são, por definição, transnacionais. Viveiros de Castro descarta o perfilamento à condição de produto dependente da reflexão científica metropolitana, afirmando, em reversão ou transvaloração nietzschiana, que são, de fato, os metropolitanos que dependem de nós, ou pelo menos que teriam muito a aprender com os índios brasileiros. A reversão remete a um re-equilíbrio da dívida (“...minha análise devia...”), e embaralha o esquema constitutivo, temporal, colonial: Não somos nós - subentendido, nós, brasileiros, etnólogos - que somos constituídos por eles - subentendido, a etnologia francesa; mas eles que são "antes" - notem a preposição determinante aqui - constituídos pela "etnologia brasileira", ressaltando-se o ligeiro, mas significativo, deslizamento entre indígenas e a etnologia, eles e nós, que infiltra sub-repticiamente o possessivo de "nossos" índios, a quem nos identificamos. O tabuleiro das posições se complica quando Viveiros de Castro nos informa que o interlocutor que o provocara era o jamaicano Stuart Hall, "um dos fundadores dos Cultural Studies britânicos", explica-nos o antropólogo. O bem posto 
da resposta, que pareceu satisfazer Stuart Hall no momento, deixou, no entanto, o brasileiro mordido, o que comprova o acerto da provocação. De certa forma o artigo em que se encontra descrita a cena é uma resposta desdobrada e estendida à acusação implícita do jamaicano.

Não creio exagerar ao ressaltar que o discreto enfrentamento que se esboça aqui, entre, de um lado, o mais brilhante e original herdeiro brasileiro da etnologia levistraussiana, e os estudos culturais, na pessoa de um de seus mais rigorosos pensadores, tem valor emblemático, e contém, de forma cifrada, a contraposição entre o que Silviano Santiago chamará em textos recentes, aos quais retornarei em seguida, o cosmopolitismo dos ricos e dos pobres, o "antigo multiculturalismo", "de que o Brasil e demais nações do Novo Mundo são exemplo", ${ }^{*}$ e o novo multiculturalismo, dos movimentos contemporâneos de minorias. * As coisas, no entanto, não são tão simples, e as cartas mais uma vez se embaralham: todo e qualquer multiculturalismo contemporâneo é programado pelo "descentramento" etnográfico, tema caro a Silviano, em citação célebre de Derrida, ${ }^{*}$ já que é na etnologia, enquanto má consciência e reverso da colonização, ciência humana desconstrucionista por definição, e repetição de Jean-Jacques Rousseau, que se encontra a primeira fórmula de subjetivação minoritária: a do indígena americano.

Viveiros de Castro sintetiza o problema a que remetia a provocação de Stuart Hall em termos de duas proposições opostas: "O que a antropologia deve teoricamente aos povos que estuda?, * de um lado, opondo-se ao poder estruturante dos "campos acadêmicos de onde provêm os antropólogos", ${ }^{*}$ de outro. A resposta de Viveiros de Castro buscará uma "sinergia dialógica" entre as duas posições, entre sujeito e objeto do saber científico, correspondendo a uma "rotação de perspectiva", o que não está de todo desligado do tema fundamental de sua pesquisa sobre o perspectivismo ameríndio: trata-se de demonstrar como - citando Viveiros de Castro -" numerosos conceitos, problemas, entidades e agentes propostos pelas teorias antropológicas se enraízam no esforço imaginativo das sociedades mesmas que elas pretendem explicar".* A aposta da antropologia, retomando o passo levistraussiano, é, em outros termos, distinta, por exemplo, do construtivismo radical, que os estudos coloniais e culturais abraçam, com quem Viveiros de Castro, em particular, neste artigo e em outros, e a antropologia como um todo, polemizam, chamando-os de "antiantropólogos" - ele menciona dentre
* (SANTIAGO, Silviano. "O cosmopolitismo do pobre" Em: O cosmopolitismo do pobre. Crítica literária e crítica cultural. Belo Horizonte: Ed. UFMG, 2004: 54.)

* (Ibidem: 59 et seq.)

* (DERRIDA, Jacques. "La structure, le signe et le jeu". In: L'écriture et la différence. Paris: Éditions du Seuil, 1967: 414.)

* (CASTRO, Eduardo Viveiros de, op. cit.: 152 .)

*(Idem.)

* (Ibidem: 153.) 
outros Homi Bhabha, e Edward Said.* Traduzindo o debate nos termos que nos interessam aqui, eu diria que a aposta dos estudos culturais é a de que não apenas não há sociedade indígena fora de uma situação de contato com a sociedade ocidental, mas que "tudo nessa sociedade se explica pela situação de contato" com a situação ocidental. ${ }^{2 *}$ A postulação de que as sociedades indígenas são precisamente constituidas pelo saber ocidental, e pela antropologia em particular, consiste em uma "missão especular", em cuja crítica a antropologia jogará todas as suas fichas. É preciso, ao contrário, estabelecer o parâmetro inverso, da sinergia entre dois construtivismos, para se chegar ao ponto em que o indígena terá pensado de fato, pela primeira, vez o ocidental.

É aqui, portanto, que desembocamos em Silviano Santiago, mais precisamente no célebre deslocamento da estratégia borgiana, de "Pierre Menard, autor do Quixote", nosso ponto de entrada e chegada no tema de hoje. Tentarei, em primeiro lugar, reconstituir em linhas gerais esta estratégia tal qual ela se inscreve na crítica de Silviano. Refiro-me a uma série de textos-chave que, de forma recorrente, à medida que os periódicos volumes de coletâneas de seus ensaios vão sendo publicados ao longo dos anos, constroem um programa único do que gostaria de chamar a "formação do sujeito colonial". Todos partem, é claro, de "O entre-lugar do discurso latino-americano", texto em todos os sentidos emblemático do que estou descrevendo, inclusive em sua situação de discurso. Situado literalmente entre três línguas, países e culturas, escrito em 1969, foi lido em francês em uma conferência na Universidade de Montreal, em 1971, traduzido e publicado no mesmo ano em inglês, quando Silviano lecionava em SUNY, Buffalo, nos Estados Unidos, e afinal retraduzido para o português, em 1978, e incluído em Uma literatura nos trópicos, após o seu retorno definitivo para o Brasil em 1974. A analogia com a cena inicial de que partimos, o simpósio de Viveiros de Castro em Manchester, é evidente: trata-se sempre do périplo do intelectual brasileiro ou latino-americano pela metrópole. Simétrico inverso da viagem de captura da empresa colonial, em sua fase de acumulação primitiva, e seu antídoto etnográfico: a viagem de formação que configura a Bildung do intelectual cosmopolita "rico", qualificará adiante Silviano: Henry James, T. S. Eliot, Murilo Mendes, elencados em "Por que e para

${ }^{2}$ Estou deslocando o sentido das frases de Viveiros de Castro. 
que viajam os europeus?”. "Mas a lista é imensa, e contém praticamente o ciclo inteiro dos "demiurgos do Brasil", na expressão de Francisco de Oliveira: Gilberto Freyre, Sérgio Buarque de Holanda e Caio Prado Júnior, isto é: o cerne das narrativas brasileiras de formação, na viagem em que o intelectual brasileiro, "desterrado em sua própria terra", como diria Sérgio Buarque de Holanda, tenta, impossivelmente, pôr termo ao seu exílio.

A série de textos programáticos de Silviano que retornam a este primeiro, em torno dos quais montarei meu argumento, é formada por "Apesar de dependente, universal" e "Uma ferroada no peito do pé" (ou o chamado "Texto da semente"), incluídos em Vale quanto pesa (1982); o já mencionado "Por que e para que viaja o europeu?", de Nas malhas da letra (1989); "Atração do mundo políticas de globalização e de identidade na moderna cultura brasileira" e "O cosmopolitismo do pobre", na coletânea de mesmo nome (2004); "Destinos de uma carta" e "A viagem de Lévi-Strauss aos trópicos" em Ora (direis) puxar conversa (2006).

Este arquitexto, o texto-matriz de todos os outros, "O entrelugar no discurso latino-americano", é construído em três grandes planos-sequência, em que o mesmo problema, a constituição deste "personagem conceitual", o "escritor latino-americano", é desdobrada em três cenários distintos, configurando a cada vez duas entradas distintas: a patologia colonial e seu antídoto ou reversão. O primeiro plano é quinhentista, e é montado a contrario a partir do antídoto: o ensaio "Dos canibais" de Michel de Montaigne, e sua repetição teórica na etnologia de Lévi-Strauss, mais especificamente em seu livro autobiográfico, Tristes Trópicos, opondo-se à "cena primitiva” em que se institui o paradigma da colonização, armada na "Carta a El Rey" de Pero Vaz de Caminha, e encenada na primeira missa. Este Urtext, ou arquitexto (da mesma forma que "O entre-lugar..." é o arquitexto de Silviano), é a "certidão de nascimento" do sujeito colonial brasileiro, ao qual retornarão as duas grandes repetições da origem brasileira: o indianismo romântico e o modernismo, ambos antídotos para os quais Silviano se voltará com frequência (sobretudo Alencar e a antropofagia). É portanto a cena da primeira missa que fixa de maneira paradigmática os papéis do indígena e do colonizador. $\mathrm{O}$ indígena, dúctil, mímico, que macaqueia os gestos dos cristãos "descobridores", "imitação totalmente epidérmica”, * "imagem refletida”, * em que se reflete o colono narcisista. A esta cena Silviano retornará também inúmeras
* (SANTIAGO, Silviano, op. cit.: 203.)

* (SANTIAGO, Silviano. "O entre-lugar no discurso latino-americano". In: Uma literatura nos trópicos. São Paulo: Perspectiva, 1978: 15.)

* (SANTIAGO, Silviano. "Apesar de dependente, universal". In: Vale quanto pesa (Ensaios sobre questões politico-culturais). Rio de Janeiro: Paz e Terra, 1982: 15.) 
* (SANTIAGO, Silviano. "O entre-lugar...", loc. cit.: 16.)

* (SANTIAGO, Silviano. "Apesar...", loc. cit.: 17.)

*(SANTIAGO, Silviano. “Por que e para que viaja o europeu?". In: Nas malhas da letra. Ensaios. São Paulo: Companhia das Letras, 1989: 192-193.)

*(SANTIAGO, Silviano. "Entre-lugar...", loc. cit.: 16; "Apesar...", loc. cit.,: 17.) vezes, sobretudo nos textos citados, ${ }^{3}$ no que configura uma espécie de "estádio do espelho" lacaniano colonial, em que se forma o sujeito brasileiro (ou latino-americano) como ficção, a partir de um roubo, expropriação, ação de despejo originárias, da alteridade indígena, constituída como aço ou suporte do espelho, Outro especular do europeu, projeção única de sua identidade europeia. ${ }^{4} \mathrm{O}$ paradigma desconstrucionista a que remete esta colocação comunica-se com o que chamei acima de "construtivismo radical": a origem brasileira tal qual contida na sociedade indígena é para sempre rasurada, "apagada completamente pelos conquistadores",* em uma operação de violência ilimitada e sem resto, de forma que teremos que nos remeter sempre a este documento de nascimento, os textos coloniais, dentre os quais, e de forma inaugural, à carta de Caminha, para resgatarmos sob a forma de rastro, pegada apagada, o vazio de origem que expressam. Nesse sentido, como já podemos suspeitar, há aqui uma polêmica surda com a etnologia, já que Silviano lê Lévi-Strauss basicamente a partir de Derrida, confronto que ele retomará, mas por um outro viés, bem tardiamente, já bem distanciado do desconstrucionismo, no longo texto sobre a "Viagem de Lévi-Strauss aos trópicos", cujo antídoto será em texto "ficcional" Viagem ao México de Antonin Artaud (1995). A colonização, em outras palavras, instala um "padrão cultural",* uma "negação dos valores do Outro",* uniformizando e abolindo as diferenças tanto do mundo medieval conhecido, que o colono traz consigo, quanto a pluralidade tribal que encontra na terra "descoberta", ao estatuir o poder do Um, sob a forma da unidade religiosa (um só deus), política (um só rei) e linguística (uma só língua).* Está constituído o paradigma da colonização, com seus polos simétricos: o colonizador ativo, constituinte, modelo, Mesmo, autocentrado, essência monolítica, de um lado; e o colonizado passivo, constituído, cópia e imitação, reflexo alterado do Mesmo, descentrado, inessencial, de outro.

O segundo plano-sequência, que se sucede a este, situa-se no campo do discurso da crítica literária, no momento em que Silviano intitula "neocolonial", e que repete em outros termos a polaridade original. Desta vez temos, de um lado, o crítico conservador universitário, instituído pela disciplina da literatura comparada,

\footnotetext{
${ }^{3}$ A que se deve acrescentar ainda um outro, "A palavra de Deus".

${ }^{4}$ Silviano não cita Lacan, embora a referência seja bastante explícita, sobretudo em "Apesar de dependente, universal".
} 
que faz ofício de inventariar as fontes e influências, e que tornam o texto estruturalmente dependente de um texto originário e original para sempre inacessível. Este crítico, dublê de padre ascético nietzschiano e fiscal do FMI das letras, que contabiliza o serviço da dívida literária do autor latino-americano, enclausurando-o na posição de cópia servil, para sempre em déficit e endividado para com a originalidade europeia. A esta nova patologia, Silviano opõe uma nova metodologia crítica, emprestada à teoria francesa, mais precisamente a Barthes, Foucault e Derrida, que retomam o caminho aberto pelo "descentramento" etnográfico de Lévi-Strauss, revertendo a hierarquia estabelecida entre cópia e modelo, a partir de uma retomada em larga escala da ontologia ocidental como um todo, privilegiando a cópia e o texto segundo, em detrimento do texto modelar e original. Trata-se de um discurso crítico que se pautará única e exclusivamente pelo "valor crítico da diferença".* A operação crítica barthesiana de escrever os textos lidos - os textos escrevíveis -; a tradução e escrita derridiana; e o arquivo flaubertiano de Bouvard et Pécuchet de textos “já escritos”, isto é, o tema do "livro sobre livros", emprestada de Foucault, * contêm um diagnóstico sobre a modernidade crítico-literária, utilizável pelo escritor/crítico latino-americano: a de que todos os textos são de fato segundos, e de que todo o texto primeiro é segundo com relação a um outro. Esta generalização do intertexto vai ser postulada em ensaios de Barthes, contemporâneos ao de Silviano, que ele não cita, mas que poderia conhecer, "A morte do autor, e "Da obra ao texto", dentre outros.

E finalmente, um terceiro plano-sequência, desta vez, literário, mais especificamente argentino, que retoma o antídoto teórico francês e demonstra o seu funcionamento em dois exemplos: $62 \mathrm{de}$ Julio Cortázar e "Pierre Menard, autor do Quixote" de Jorge Luis Borges. Não vou entrar no detalhe destas análises célebres, basta lembrar aqui que a estratégia da escrita, nos dois casos, consiste em um movimento autorreflexivo, a partir do qual a escrita se dobra sobre si mesma: a expressão em francês refletida no espelho, "Je voudrais um château saignant", retraduzida transformadoramente em espanhol, politiza a frase gastronômica, e, agressivamente, sangra o castillo feudal e colonialista, a agressão ao modelo se dando pela tradução diferencial do significante. Da mesma forma, o projeto aparentemente absurdo de escrever não um outro Quixote, mas $o$ Quixote, tal qual inscrito na fábula de Borges, consiste em literal-
*(SANTIAGO, Siliviano, "O entre-lugar...", loc. cit.: 21.)

* (FOUCAULT, Michel. "La Bibliotèque fantastique". In: Dits et écrits, vol. 1. Paris: "Quarto" Gallimard, 2001: 338-340.) 
* (DERRIDA, Jacques. Of Grammatology. Trad. Gayatri Spivak. Baltimore: The Johns Hopkins University Press, 1976: 144-145.)

* (SAID, Edward. "Abecedarium culturae": 38, Apud, MACKSEY, Richard e DONATO, Eugenio. "The Space Between - 1971". In: The Structuralist Controversy. The Languages of Criticism \& the Sciences of Man. Richard Macksey e Eugenio Donato (ed.). Baltimore: The Johns Hopkins University Press, 1972: xiii.) mente fazer desaparecer a diferença entre modelo e cópia, de forma a que a cópia se substituía ao modelo.

Esta é precisamente a operação do suplemento, que Silviano empresta de Derrida, em seu longo ensaio sobre o Ensaio sobre a Origem da Linguas de Rousseau, em Da Gramatologia, adaptando-o a suas próprias necessidades. Resumindo brevemente a problemática construída no texto de Derrida, apenas para mostrar o deslocamento a que o submete Silviano, teremos algo como: a escrita (como arte, tekhné, representação, convenção) vem suplementar algo que é pleno e repleto em si, a natureza ou a origem. Mas, pelo mesmo gesto, o que é presente em si e autossuficiente, é substituído por aquilo que o representa - o signo preenche o vazio da plenitude ausente e assume o seu lugar. Nos dois sentidos de suplemento - enquanto acréscimo e substituto - no entanto, ele é exterior, estranho, outro, com relação ao que é acrescido ou substitui.* Em outras palavras, o suplemento determina uma exterioridade ou autonomização daquilo a que se acrescenta ou substitui. O significante castillo sangriento se substitui ao original francês que traduz, agride-o, destrói-o; o Quixote de Pierre Menard é superior ao de Cervantes, substituindo-se a ele.

A questão do "entre-lugar" é emprestada, salvo engano, de um texto de Eugenio Donato e Richard Macksey - o ensaio de Silviano é dedicado a Donato e a sua mulher, Sally - que introduz os Anais do Simpósio Internacional, publicado com o título de The Structuralist Controversy. The Languages of Criticism and the Sciences of Man, ocorrido entre 18 e 21 de outubro de 1966, em Johns Hopkins, Baltimore, e que marca a introdução do pós-estruturalismo francês nos Estados Unidos. Dele participaram Lacan, Barthes, Derrida, Deleuze, Foucault, Girard, entre outros. A expressão é, por sua vez, tomada de um ensaio de Edward Said. Donato e Macksey descrevem o status quo da literatura hoje em dia, limitada aos substitutos sígnicos de uma presença perdida, o que nos força a articular o que Said chamara de "espaços vazios entre as coisas, palavras e ideias.”* Não menciono estas referências por exercício cioso da crítica das fontes e influências, cuja falência Silviano já apontara, mas apenas para situar a sua escrita na proximidade desta recepção de primeira hora do pensamento francês nos Estados Unidos, onde Silviano se encontrava na época, nas vizinhanças dos amigos mais próximos de Silviano. A ele poderíamos aplicar o comentário irônico de Mário de Andrade, sobre a acusação 
de plágio que supostamente cometera na escrita de Macunaíma, ao copiar do antropólogo alemão Koch-Grunberg, que o próprio Silviano estuda no maravilhoso "História de um livro": "O que me espanta e acho sublime de bondade, é os maldizentes se esquecerem de tudo quanto sabem, restringindo a cópia a Koch-Grunberg, quando copiei todos".*

Ao retomar o problema da formação do sujeito colonial em "Apesar de dependente, universal", Silviano recoloca a questão no contexto da reflexão uspiana de Paulo Emilio Salles, Gilda de Mello e Souza e Antonio Candido. Aqui, trata-se basicamente de incorporar os temas da teoria da dependência de Raúl Prebisch e Celso Furtado para a crítica e a produção literária. Para ir direto ao ponto, e economizar tempo, é perfeitamente claro que Antonio Candido, quando escreve, em "Literatura e subdesenvolvimento", que um "estágio fundamental na superação da dependência [literária brasileira] é a capacidade de produzir obras de primeira ordem, influenciadas, não por modelos estrangeiros imediatos, mas por exemplos nacionais anteriores", * está formulando algo como uma "substituição de importaçōes" literária. Mas Silviano, ao retraduzir o tema do suplemento de "O entre-lugar do discurso latinoamericano" em termos de um problema da teoria da dependência, toma o problema por um viés distinto. Não enfatiza a constituição orgânica de uma linhagem, o que Candido chama de "causalidade interna", mas a inserção universal do texto dependente através de uma dupla coerção: a reflexão de dados empíricos e a "reflexão sob (e não sobre) a cultura ocupante", ${ }^{*}$ que retoma o problema do suplemento inscrito anteriormente. A emancipação do caráter dependente da literatura não se faz pela denegação da dependência, mas, ao contrário, como amor fati nietzschiano, pela afirmação de sua inevitabilidade, ${ }^{*}$ enfatizando a força coercitiva da literatura dominante, em outras palavras, repetindo-a reflexivamente, por meio de "um salto por cima das imitaçôes e das sínteses enciclopédicas etnocêntricas"* que nos constituem.

Ao final do ensaio, Silviano retorna explicitamente aos termos da discussão de Uma literatura nos trópicos, referindo-se à estratégia borgiana inscrita em seu ensaio "Eça, autor de Madame Bovary”. A reversão da ordem cronológica e lógica, colocando o que sucede no lugar do que antecede, a consequência no lugar da causa, não é simples exercício lúdico, mas está a serviço da constituição de "um suplemento crítico paradoxal". ${ }^{*} \mathrm{O}$ suplemento é pre-
* (SANTIAGO, Silviano. "História de um livro". Em: Nas malhas da letra, loc. cit.: 131.)

* (CANDIDO, Antonio. "Literatura e subdesenvolvimento". In: Educação pela noite \& outros ensaios. São Paulo: Ática, 1989: 153.)

* (SANTIAGO, Silviano. "Apesar...", loc. cit.: 21.)

* (Ibidem: 22.)

* (Idem.)

* (Ibidem: 23.) 
* (Idem.)

* (Ibidem: 24.)

* (CANDIDO, Antonio: 23. Apud SANTIAGO, Silviano, "O cosmopolitismo do pobre", loc. cit.: 12.)

* (Idem.)

* (Ibidem: 22.) cisamente aquilo que se acrescenta ao original (no caso, o Madame Bovary de Flaubert) e o diferencia dele, a despeito da dependência estrutural da cultura francesa que caracteriza a geração de Eça em Portugal, tornando-o, paradoxalmente, mais original do que o texto primeiro, mais original do que Flaubert. Como se dá isso? Ao incluir na escrita romanesca o suplemento da leitura, fazendo-a conter em si, como explica ele, ao mesmo tempo, "a representação do texto dominante e uma resposta a esta representação no próprio nível da fabulação", ${ }^{*}$ que o texto segundo se constrói. $\mathrm{O}$ texto dependente repete em si mesmo o texto dominante como arquivo de leitura, citando-o, e, fazendo isso, universaliza-o, já que explicita nele a sua condição essencial de texto escrito a partir de outros textos, que é a de todos os textos. Esta resposta, contida na dobra sobre si mesmo, torna o texto segundo superior ao primeiro, já que ele contém o primeiro mais a sua leitura. Observe-se que, mise-em-abyme oblige, a operação suplementar se dá precisamente no momento em que Silviano cita os seus próprios textos, retomando, ao nível da fabulação, a discussão de Uma literatura nos trópicos, mas traduzindo-a para um outro (o mesmo) contexto: o da teoria da dependência, e o da construção de uma "universalidade diferencial", que neste texto ainda se inscreve de forma vaga, como que inscrita em suas margens.*

A nova síntese, apresentada nos dois primeiros ensaios de $O$ cosmopolitismo do pobre, "Atração do mundo" e o ensaio que dá nome à coletânea, retoma o fio da discussão a partir de Minha formação de Joaquim Nabuco, isto é, aquele que é, salvo engano, o modelo de todas as narrativas de formação brasileiras, a começar pela de Antonio Candido, na Formação da literatura brasileira, cuja definição de cultura brasileira como sistema constituído a partir da "síntese de tendências particularistas e universalistas", ${ }^{*}$ o intelectual cosmopolita, à la Nabuco, realiza. A cena primitiva da primeira missa reinscreve-se aqui nas "metáforas tomadas de empréstimo à representação teatral", * que instalam Nabuco aposentado, em 1900, na poltrona de sua casa no Brasil como espectador do que se representa no teatro da Política com "P" maiúsculo, situado na Europa, e não em seu país. Protótipo, escreve Silviano, do "wired citizen", Nabuco se comunica com o mundo por meio do telégrafo e foge da mediocridade da vida política nacional (com "p" minúsculo). A partir da figura de Nabuco, Silviano diagnostica toda uma patologia das elites esclarecidas, cosmopolitas, brasileiras, que comparti- 
lharam, seja na interiorização do dado exterior, como definição do "sentimento íntimo" que define o "instinto de nacionalidade" literária, em Machado de Assis, ${ }^{*}$ seja na comunhão com a "tragédia de Nabuco", diagnosticada em Drummond por Mário de Andrade,* esta mesma adoção interiorizada do paradigma universal que nos constitui destituindo-nos. $\mathrm{O}$ universalismo dará origem, por sua vez, a dois modelos distintos, que emergiram respectivamente nos anos 20, com o modernismo, e nos anos 30, com o economicismo: o cânone etnográfico modernista e o realismo sociológico da década seguinte. Ambos os modelos entram em crise nos últimos anos: o cânone etnográfico modernista perde o seu otimismo a partir do golpe militar de 1964, quando a utopia do microcosmo neolítico ou folclórico se confunde com as camadas miseráveis da população. O cânone economicista teria perdido terreno também com um desligamento do apoio das massas. Aqui convém um reparo: no texto de 1995, Silviano não poderia ter sabido do destino auspicioso (poderia dizer, se vocês me perdoarem o péssimo trocadilho, uspicioso) que este cânone economicista teria a partir da eleição de Lula em 2003, já que é precisamente ele que é empossado com o presidente.

A crítica a estes dois modelos universalizantes, de um "cosmopolitismo de rico", vem sendo formulada, no entanto, ultimamente, por novos cosmopolitismos, bastante diferentes destes cosmopolitismos da elite branca e masculina, e que funcionam como antídoto a ele. A diferença que vinha pautando os antídotos nas sínteses anteriores: o método teórico francês que negligencia a caça às fontes e influências, e estabelece como "único valor crítico a diferença", a "universalidade diferencial" do texto que reflete a situação de dominação, aqui se materializa, pela primeira vez, em sínteses empíricas, com a emergência de novos sujeitos ligados a movimentos sociais e a organizaçoes não governamentais (ONGs), de que quem sabe o ameríndio "transnacional" seria a primeira versão. O sujeito colonial, que sintetiza em si o particular e o universal, que media a forma universalizante do particular, torna-se ocioso, sendo substituído por sujeitos que se ligam diretamente ao mundo internacionalizado, sem necessitar passar pela mediação nacional. Aqui também, as linhas se bifurcam: uma corrente simpática ao modelo norte-americano, já que é este, sem sombra de dúvidas, o

* (Ibidem: 17.)

* (Ibidem: 24 .)

* (SANTIAGO, Silviano. "O entre-lugar...", loc. cit.: 21.) 
novo modelo dominante, que procura adaptar o multiculturalismo à la americana ao Brasil (podemos pensar aqui na discussão sobre cotas raciais, agora institucionalizada sob a forma de lei federal); e uma corrente antipática ao modelo norte-americano, atenta ao neocolonialismo instituído sob a forma de importação maciça de produtos da mídia, e que, desta forma, se articula em movimentos refratários à representação midiática, como o Movimento dos Sem-Terra, e a música sertaneja. Que ambos se utilizem, é óbvio, da mídia, enquanto movimentos essencialmente cosmopolitas, não implica em nenhuma contradição.

A premissa metodológica da diferença como entendida por Silviano, mantém-no, no entanto, reticente com relação às possibilidades de autonomização destes novos sujeitos cosmopolitas, deste cosmopolitismo por assim dizer "de pobre". Será que estas novas articulações e alianças internacionais, que constituem sujeitos marginalizados e prescindem da mediação do estado-nação, não reconfiguram um novo cenário de dependência, desta vez diante de organizaçôes não governamentais benévolas e bem intencionadas? - Silviano talvez se perguntasse. Em outros termos, será que as novas sínteses não refazem um paradigma semelhante ao colonial, com aderências mais complexas e difíceis de identificar, mas que não chegam a poder dar origem a novos sujeitos independentes, e com plenos direitos? De todo modo, não resta dúvida de que esse cenário retranscreve, em outros termos, o modelo de "apesar de dependente, universal”, de que é uma prefiguração certamente não involuntária. Portanto, não um sujeito autônomo, quem sabe um quase-sujeito, construído na precariedade da dobra repetitiva com que se insere na rede internacional, antenado, wired - mas como todos os outros. Nós outros.

João Camillo Pena é professor de literatura comparada e teoria literária na UFRJ. Autor de artigos na área de crítica da violência, de um livro de poesias, Parador (Móbile editorial, 2011), e de um livro, no prelo, Escritos da sobrevivência (7Letras, 2013). E-mail: <jcamillopenna@gmail.com>. 